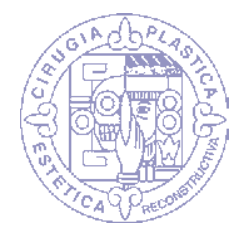

\title{
Técnica de aislamiento de la fracción vascular estromal derivada del tejido adiposo: obtención de células madre adultas para diversas aplicaciones
}

\author{
Isolation technique of the stromal vascular fraction derived from \\ adipose tissue: obtaining adult stem cells for various applications
Dr. Wilder Antonio Pérez-Willis, ${ }^{*}$ Biol. Moisés Yance-Morales, ${ }^{\ddagger}$
Dr. Wilder Armín Pérez-Soto ${ }^{\S}$

Palabras clave:

Tejido adiposo, células madre derivadas del tejido adiposo, fracción vascular estromal, terapia celular.

Keywords: Adipose tissue, stem cells derived from adipose tissue, stromal vascular fraction, cell therapy.

* Médico Especialista en Cirugía Plástica y Reconstructiva. Clínica Continental.

¥ Licenciado en Biología Humana. Hospital Arzobispo Loayza. $\S$ Médico Especialista en Cirugía Plástica y Reconstructiva. Director médico, Clínica Continental.

Los autores de este artículo no tienen conflicto de intereses qué declarar

\section{Recibido:}

20 agosto 2018 Aceptado para publicar: 12 noviembre 2018

\section{RESUMEN}

En la actualidad se sabe que el tejido adiposo está compuesto por adipocitos y fracción vascular estromal. Dentro de ésta se encuentran las células madre derivadas del tejido adiposo, mismas que se están utilizando en diversos estudios; sin embargo, al momento no hay un protocolo estandarizado para obtener dicha fracción y en muchas ocasiones son costosos ya que en algunos casos utilizan equipos automatizados. En este estudio describimos una técnica detallada de aislamiento de la fracción vascular estromal que emplea elementos básicos, económicos, con resultados óptimos, para que sean accesibles a todos los especialistas. Tomamos muestras de tejido adiposo del área abdominal de 30 mujeres de 25 a 50 años de edad, mediante una cánula de lipoaspiración. Las muestras se sometieron a aislamiento de la fracción vascular estromal con la técnica que proponemos, llevando un control con una técnica denominada clásica y se tomó como base el método enzimático. Después realizamos el conteo celular con la coloración azul de tripán por medio de una cámara de Neubauer de forma manual, obteniendo una concentración celular promedio de 427,033 células/mL de fracción vascular estromal y una viabilidad celular promedio de $79.6 \%$. También tomamos en cuenta el tiempo de aislamiento, que fue en promedio de 75.1 minutos. Concluimos que nuestra propuesta es una técnica de fácil aplicación, accesible y económica, con resultados adecuados para realizar terapias o cultivos celulares, sin que sea necesario el uso de equipos automatizados y es una base fundamental para los especialistas de cirugía plástica y reconstructiva.

\section{ABSTRACT}

It is known that adipose tissue is composed of adipocytes and stromal vascular fraction. Within this are stem cells derived from adipose tissue, which are being used in various studies; however, at present there is no standardized method for obtaining this fraction, being expensive and in some cases automated equipment is used. In this study we describe a detailed technique of isolation of the stromal vascular fraction that uses basic, economical elements, with optimal results, so that they are accessible to all specialists. We took samples of adipose tissue from the abdominal area of 30 female patients 25 to 50 years old, using a lipoaspiration cannula. The samples were subjected to isolation of the stromal vascular fraction with the technique we propose, carrying out a control with a technique called classical, based on the enzymatic method. Then we performed the cell count with the tripan blue staining by means of a Neubauer chamber manually, obtaining an average cell concentration of 427,033 cells/ $\mathrm{mL}$ of stromal vascular fraction and an average cell viability of $79.6 \%$, as well count time of isolation, which was an average of 75.1 minutes. We conclude that our proposal is a technique of easy application, accessible and economical, with adequate results to perform cell therapy or cell culture, without the need for automated equipment and is a fundamental basis for specialists in reconstructive plastic surgery.

\section{INTRODUCCIÓN}

־ $\mathrm{n}$ el campo de la cirugía plástica y medici$\amalg$ na regenerativa, la realización de terapias celulares ha tenido grandes avances en los últimos años; desde la ingeniería de tejidos (posibilidad de generar órganos por fuera del ser humano) hasta la posibilidad de tratar enfermedades diversas como enfermedad de Dupuytren, esclerodermia, infarto de miocar- 
dio, etcétera, a través del implante de células madre de diverso origen. Es por ello que la técnica de aislamiento de la fracción vascular estromal resulta relevante, ya que viene a ser el primer paso para realizar terapias celulares o ingeniería de tejidos. ${ }^{1,2}$

Las células madre adultas representan una fuente ideal para terapias celulares debido a su fácil acceso, a pesar de tener una menor capacidad de diferenciación que las células madre embriológicas. ${ }^{3,4}$ En ese sentido, el tejido adiposo representa una accesible y abundante fuente de células madre adultas con la capacidad de diferenciarse en múltiples líneas celulares a través del cultivo e ingeniería de tejidos, incluyendo tejido cartilaginoso, óseo, cardiaco, nervioso y adiposo. ${ }^{5-8}$

La fracción mononuclear del tejido adiposo referida como fracción vascular estromal (FVE) fue descrita originalmente como una «fuente de células precursoras del adipocito» por Hollenberg y colaboradores en EUA, en $1968 ;{ }^{9} \sin$ embargo, el término «célula madre multipotente derivada del tejido adiposo» (ADSC) fue reconocido en el año 2001, donde Zuk y su equipo en EUA demostraron que la FVE contiene un gran número de células madre adultas. ${ }^{5}$

Esta fracción se obtiene por un proceso enzimático del tejido adiposo que se lleva a cabo mediante la enzima colagenasa, y es el método que más se utiliza en la actualidad. ${ }^{10}$

Después de obtener esta FVE, se pueden realizar terapias celulares, una de ellas es la lipotransferencia celular asistida (CAL-Cell Assisted Lipotransference), técnica en la que se mezcla una porción de tejido graso para ser injertado junto con la FVE. Esta técnica convierte el tejido adiposo escaso en células madre abundantes, mejorando la viabilidad del injerto en un $35 \%$ y su capacidad regenerativa. ${ }^{11}$

Asimismo, la presencia de las células madre derivadas del tejido adiposo, tiene implicaciones clínicas en la lipotransferencia celular asistida (CAL), ya que las mencionadas pueden contribuir con la nueva angiogénesis en la fase aguda, por la acción de sus células progenitoras endoteliales o células liberadoras de factores angiogénicos. ${ }^{12,13}$

La CAL es utilizada actualmente en múltiples procesos estéticos como rellenos faciales, rejuvenecimiento facial y de manos, así como reconstructivo en secuelas de quemaduras, cicatrices retráctiles, reconstrucción mamaria, colagenopatías, úlceras residuales, etcétera, hechos que ya son una realidad clínica. ${ }^{11,14}$

Es por ello que los estudios han demostrado que la CAL es más efectiva, segura y regeneradora que un lipoinjerto tradicional. ${ }^{12,15}$ En este contexto, la estandarización y simplificación del proceso de aislamiento de la FVE resulta necesaria e importante para el uso en el campo de la cirugía plástica regenerativa.

A nivel mundial, diversos autores describen sus métodos de aislamiento: en Japón, $\mathrm{K}$ Yoshimura y su grupo desarrollaron el aislamiento de la FVE del tejido adiposo usando la enzima colagenasa, realizando la reacción enzimática a una temperatura de $37^{\circ} \mathrm{C}$ durante 30 minutos, con un tiempo promedio total del proceso de 80 minutos. ${ }^{16}$ Este autor realiza la CAL y es él mismo el que describió la técnica; sin embargo, no menciona los pasos para obtener la FVE.

Minteer y colaboradores de la Universidad de Pittsburgh, reportaron realizarlo por medio enzimático con un tiempo promedio de 60 a 90 minutos, incubándolo a $37{ }^{\circ} \mathrm{C} ;{ }^{17}$ sin embargo, al igual que Yoshimura, no mencionan los pasos del proceso de aislamiento de la FVE.

A diferencia de ellos, Pawitan, en Indonesia, utiliza un filtro de café para lavar el tejido adiposo y después llevar a la digestión enzimática durante 60 minutos a una temperatura de 37 ${ }^{\circ} \mathrm{C}$, con agitaciones cada cinco minutos. ${ }^{18}$

En América Latina, así como en el Perú, no se han reportado estudios acerca de la simplificación y estandarización de la técnica de aislamiento de la FVE, dificultando su aplicación y uso, ya que muchos de los especialistas no conocen del tema.

Por lo tanto, el objetivo del presente estudio fue describir una nueva técnica estandarizada y simplificada de aislamiento de la FVE derivada del tejido adiposo para la obtención de células madre adultas, que resulte de fácil aplicación y acceso para los profesionales de cirugía plástica y medicina regenerativa.

\section{MATERIAL Y MÉTODO}

Se realizó un estudio descriptivo transversal, prospectivo entre abril y octubre de 2015. Se tomaron muestras de 30 mujeres de 25 a 50 
años de edad (promedio 36), que acudieron a la Clínica Continental en Lima, Perú, lugar en el cual se procesaron las muestras para la obtención de los resultados del estudio.

El estudio contó con el consentimiento informado de las pacientes. Las muestras fueron de 50 gramos de tejido adiposo extraído de cada paciente, tomando como área dadora la

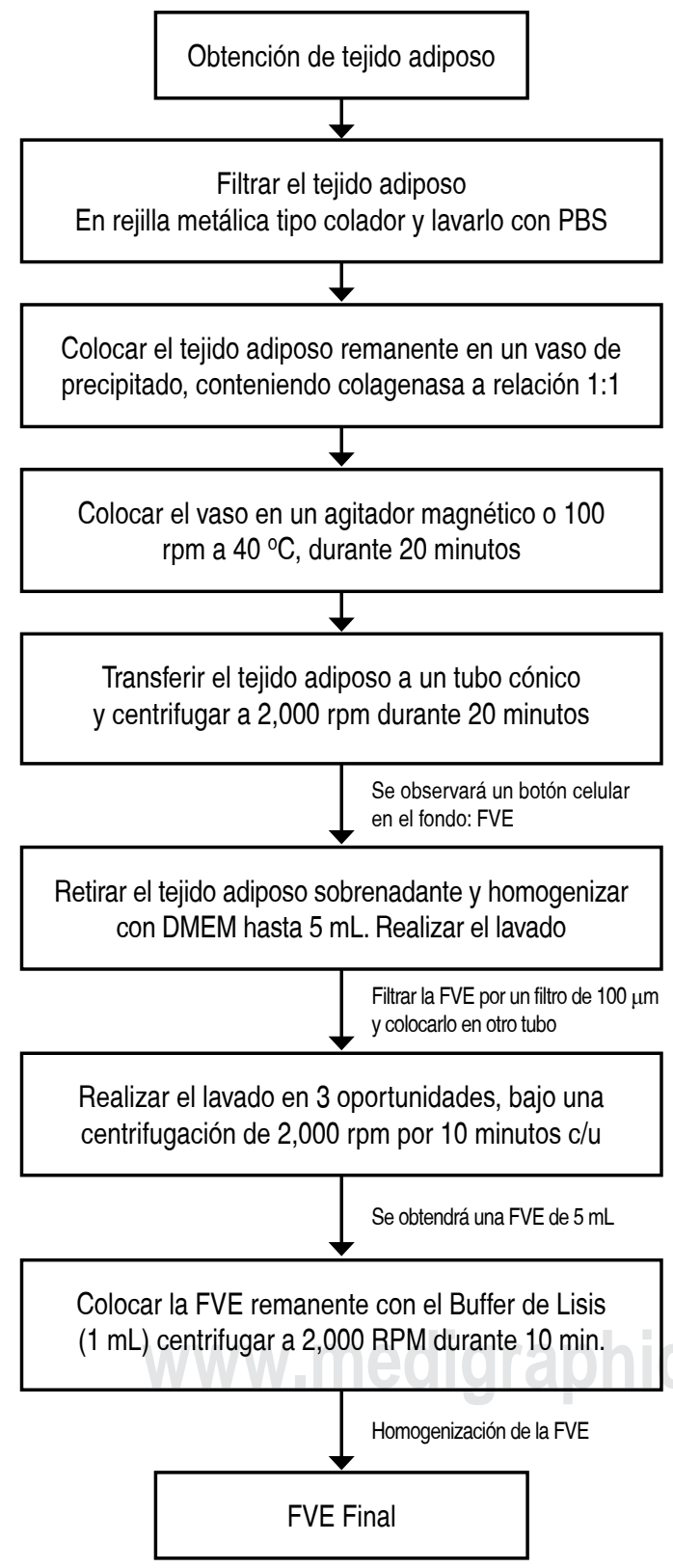

Figura 1: Flujograma de la técnica simplificada propuesta para el aislamiento de la fracción vascular estromal.

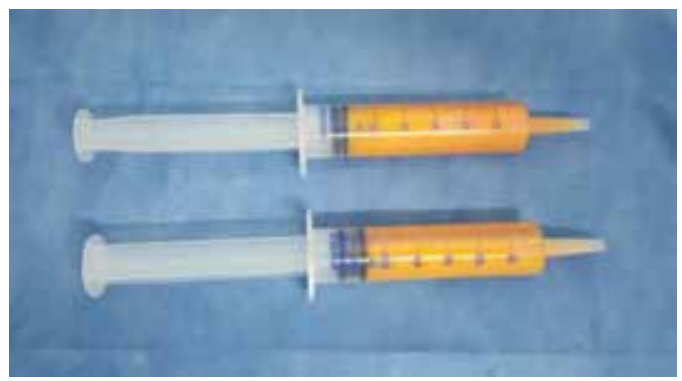

Figura 2: Extracción de tejido adiposo con cánula de $25 \mathrm{~cm}$ con orificios de $3 \mathrm{~mm}$ acompañado de solución tumescente.

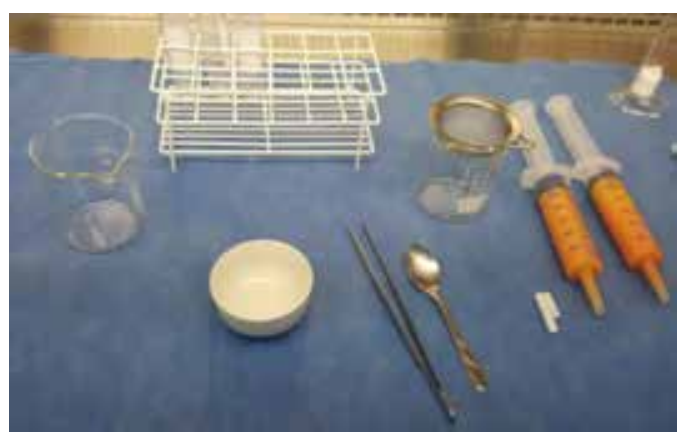

Figura 3: Preparación de la mesa de trabajo dentro de la cabina de flujo laminar.

zona abdominal inferior o periumbilical, realizando el aislamiento de la FVE mediante dos técnicas distintas. Para efectos de la investigación, se definió como «técnica simplificada» a la desarrollada en el presente estudio. La técnica simplificada propuesta en el presente estudio consistió en los siguientes pasos (Figura 1):

1. Obtención del tejido adiposo (Figuras 2 y 3).

2. Filtración del tejido adiposo (Figura 4).

3. Digestión enzimática mecánica (Figura 5).

4. Centrifugación y lavados (Figuras 6 y 7).

5. Lisis de eritrocitos (Figura 8).

Los equipos y reactivos se describen en las Tablas 1 y 2.

Como control se realizó el procesamiento de $50 \mathrm{~g}$ de tejido adiposo adicional de la misma persona, mediante una técnica que denominamos «técnica clásica», tomando en cuenta como base la descripción de Pawitan, con el objetivo de evaluar el resultado y tomarlo 
como referencia a la «técnica propuesta». La diferencia entre ambas técnicas es el tiempo de incubación con la enzima colagenasa, que es de 60 minutos, así como la temperatura de $37{ }^{\circ} \mathrm{C}$ y ambas son de carácter enzimáticomecánico. ${ }^{16-18}$

Después de la obtención de la FVE, se realizó la lectura final mediante un microscopio de luz con un objetivo de 40x; para ello se preparó $10 \mu \mathrm{L}$ de solución azul de tripán $0.4 \%$, con 10 $\mu \mathrm{L}$ de FVE, a través de una pipeta calibrada y de monto $10 \mu \mathrm{L}$. La muestra de ambas técnicas se llevó a la cámara de Neubauer o hemocitómetro y se realizó un conteo manual según la tinción de dichas células (Figura 9); aquéllas teñidas con azul de tripán (exclusión de tripán) son no viables o muertas, caso contrario con las células no teñidas, que son las células viables o vivas (Figura 10). El conteo en mención

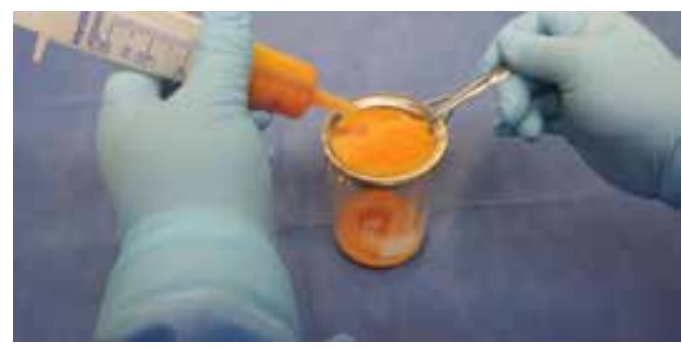

Figura 4: Filtración del tejido adiposo aspirado por un filtro de acero inoxidable tipo colador; se deja caer el líquido en un vaso de precipitado auxiliándose con una paleta metálica.

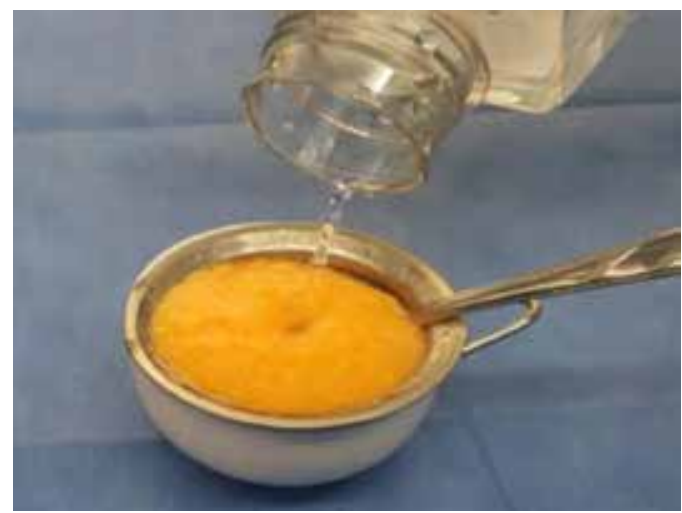

Figura 5: Lavado del remanente del tejido adiposo con PBS 1X, auxiliado con una paleta metálica estéril se deja caer el remanente en un recipiente.

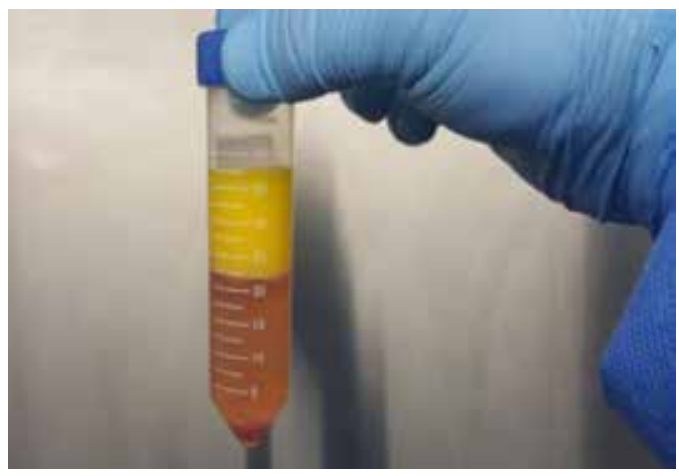

Figura 6: Después del proceso de centrifugación se observará un botón celular que es la fracción vascular estromal y un sobrenadante de tejido adiposo.

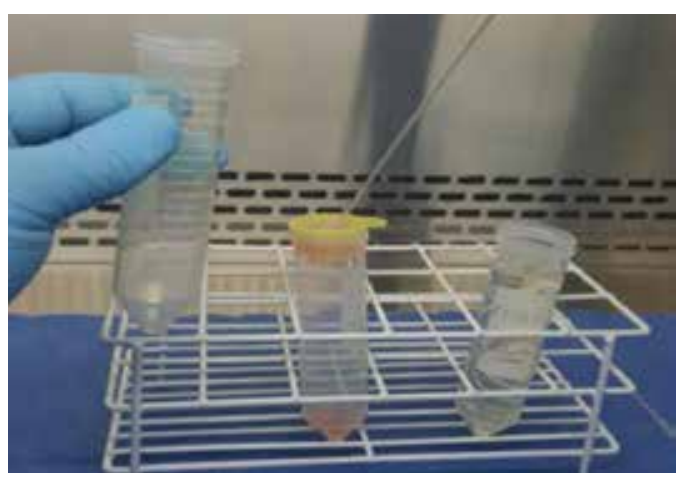

Figura 7: Lavado con DMEM llegando hasta $10 \mathrm{~mL}$ del contenido del tubo cónico hecho en tres oportunidades.

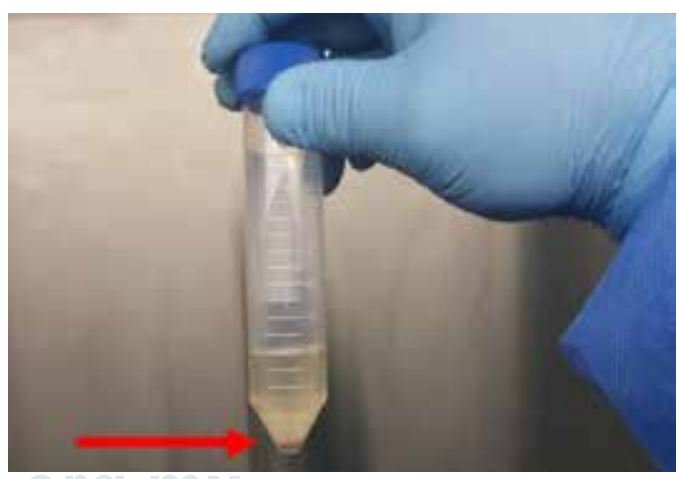

Figura 8: Se coloca $1 \mathrm{~mL}$ de buffer de lisis de glóbulos rojos y se procede a centrifugar.

sirvió para hallar la concentración celular y el porcentaje de viabilidad (Figura 11). Todos los datos se colocaron en un cuadro de datos en el programa de Microsoft Excel. 


\section{RESULTADOS}

De las 30 muestras de FVE obtenidas con la «técnica simplificada propuesta», se obtuvo un promedio de 170.8 células vivas determinadas en los cuatro cuadrantes, al igual que un promedio de 44.5 células muertas determinadas en los cuatro cuadrantes, con un conteo celular promedio de 427,033 y una viabilidad celular promedio de $79.6 \%$. El tiempo promedio de aislamiento en esta técnica fue de 75.1 minutos (Tabla 3).
De las 30 muestras de FVE obtenidas con la «técnica clásica» (basada en Pawitan), se obtuvo un promedio de 128.8 células vivas determinada en los cuatro cuadrantes, al igual que un promedio de 38.5 células muertas determinadas en los cuatro cuadrantes, con un conteo celular promedio de 322,666 y una viabilidad celular promedio de $77.2 \%$. El tiempo promedio de aislamiento en esta técnica fue de 117.1 minutos (Tabla 3).

Se obtuvo una diferencia de 42 células vivas determinadas entre ambos promedios, una

\begin{tabular}{lccc}
\multicolumn{2}{c}{ Tabla 1: Equipos utilizados en la técnica simplificada para la obtención } \\
de la fracción vascular estromal del tejido adiposo.
\end{tabular}

Tabla 2: Reactivos utilizados en la técnica simplificada para la obtención de la fracción vascular estromal del tejido adiposo.

\begin{tabular}{lccc} 
Nombre & Compañía & Número de catálogo & Comentarios \\
\hline Fosfato buffer salino (PBS 1X-estéril) & Gibco & $10010-023$ & \\
Buffer de lisis de glóbulos rojos & Roche & 11814389001 & \\
Dulbencoo's Eagle (DMEM) & Sigma Aldrich & D5030 & \\
Solución azul tripán $0.4 \%$ & Sigma Aldrich & T8154 & \\
Colagenasa tipo I (345 U/mg) & Worthington & LS004196 & \\
Filtro de nitrocelulosa de $0.2 \mu \mathrm{m}$ & Sterlitech & MCE0222550S & \\
Filtro celular de nylon $100 \mu \mathrm{m}$ & Falcon & 352360 & \\
Tubos cónicos estériles & Falcon & & Se requieren dos unidades \\
Vaso de precipitado de vidrio $250 \mathrm{~mL}$ & Isolab & & Se requieren cuatro unidades \\
Vaso de precipitado de vidrio $400 \mathrm{~mL}$ & Isolab & & \\
Pipeta Pasteur de vidrio $5 \mathrm{~mL}( \pm 0.03)$ & Borosil & & \\
Barra magnética con anillo $25 \times 6 \mathrm{~mm}$ & Azlon & SWN504 & \\
Aspirador de pipeta manual (hasta $10 \mathrm{~mL}$ ) & Easy8 & 2047EAS8010001 & \\
Filtro metálico tipo colador & S/N & S/N & \\
\hline
\end{tabular}




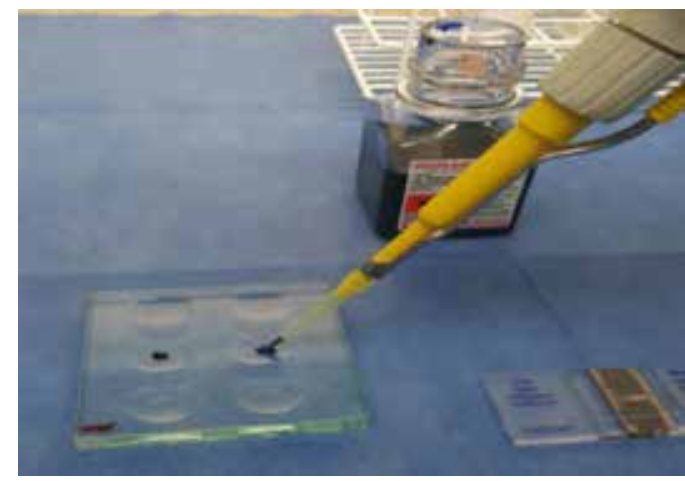

Figura 9: Preparación de la muestra para la cámara de Neubauer o hemocitómetro.

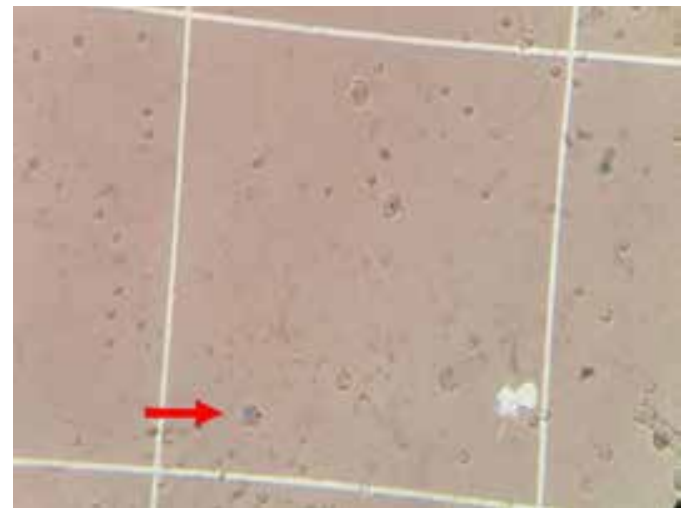

Figura 10: Visualización de la fracción vascular estromal al microscopio en la que se observan células muertas teñidas de color azul. El tinte no puede penetrar la membrana de una célula viva.

diferencia de seis células muertas determinadas en los cuatro cuadrantes; una diferencia de promedios de conteo celular de 104,367 células por mililitro y una diferencia en los tiempos de procesamiento de 42 minutos a favor de la técnica propuesta.

\section{DISCUSIÓN}

Los resultados obtenidos en este estudio dan una contribución importante en el campo de la cirugía plástica regenerativa en Latinoamérica, al describir una técnica de aislamiento de la FVE del tejido adiposo (fuente de células madre adultas), la cual puede ser accesible y de fácil aplicación para los profesionales que se desempeñan en este campo. Conviene resaltar que en Latinoamérica no hay un protocolo ideal, adecuado, ni registrado para realizar el aislamiento de la FVE, por eso tomamos como referencia a Pawitan, Minteer y Yoshimura, para encontrar las diferencias al realizar el aislamiento en nuestros pacientes.

En cuanto al tiempo de aislamiento de la FVE, la reducción del mismo a un promedio de 75.1 minutos, sin afectar la cantidad de células nucleadas halladas con un promedio de la misma de 427,033 cel/mL, mismo que se encuentra dentro de los márgenes estimados propuesto por Yoshimura y Minteer, ${ }^{16,17}$ significa la mejora de un proceso que por años se ha desarrollado en más tiempo por diversos autores y con técnicas y equipos más complejos, que dificultan el uso de la técnica. Asimismo, la viabilidad celular en este estudio fue de $79.6 \%$, superior al descrito por Pawitan de $55 \%$ en su estudio. ${ }^{16-18}$

En cuanto a la digestión enzimática, Yoshimura utilizó un equipo Incubador-Agitador, en el cual realiza la agitación del tejido adiposo de forma continua por 30 minutos aproximadamente, durante la cual se mantuvo una temperatura de $37^{\circ} \mathrm{C}$, similar a nuestro procesamiento, siendo la técnica propuesta con 20 minutos de digestión; sin embargo, lo realizó con un equipo llamado Incubador-Agitador que aumenta el costo del procesamiento. ${ }^{16}$ Por otra parte, Pawitan hace la digestión enzimática durante 60 minutos con agitaciones cada cinco minutos a una temperatura de $37^{\circ} \mathrm{C}$, aumentando así el tiempo de procesamiento. ${ }^{18}$ Ambas técnicas difieren de la que proponemos en este estudio, en la que hicimos la agitación del tejido adiposo en un vaso de precipitados durante 20 minutos, auxiliada con un agitador magnético, utilizando mayor temperatura $\left(40^{\circ} \mathrm{C}\right)$ que los

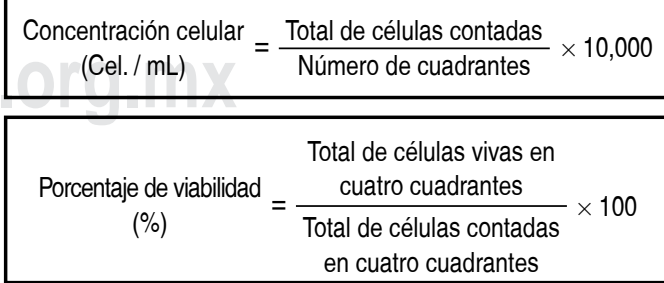

Figura 11: Fórmulas para determinar la concentración y la viabilidad. Celular. 
Tabla 3: Comparación de resultados obtenidos entre la técnica simplificada propuesta y la clásica.

\begin{tabular}{lccccc} 
& $\begin{array}{c}\text { No. de células vivas } \\
\text { determinadas en } 4 \\
\text { cuadrantes }\end{array}$ & $\begin{array}{c}\text { No. de células muertas } \\
\text { determinadas en } 4 \\
\text { cuadrantes }\end{array}$ & $\begin{array}{c}\text { Concentración } \\
\text { celular (cel/mL) }\end{array}$ & $\begin{array}{c}\text { Viabilidad } \\
\text { celular (\%) }\end{array}$ & $\begin{array}{c}\text { Tiempo } \\
\text { (min) }\end{array}$ \\
\hline $\begin{array}{l}\text { Técnica simplificada } \\
\text { propuesta } \\
\begin{array}{l}\text { Técnica clásica } \\
\text { (Según J. Pawitan) }\end{array}\end{array}$ & 170.8 & 44.5 & 427,033 & 79.6 & 75.1 \\
\hline
\end{tabular}

autores mencionados, disminuyendo de esta forma el tiempo y costos del procedimiento de manera considerable.

Los resultados mencionados en este estudio se podrían atribuir a tres factores: el lavado previo del tejido adiposo, el uso de temperatura a $40{ }^{\circ} \mathrm{C}$ y la agitación constante del tejido adiposo.

En cuanto al lavado del tejido adiposo con PBS con un filtro de acero inoxidable tipo colador, reduce el tiempo de lavado de la muestra después de ser extraída; además, según lo descrito por Pawitan, este procedimiento mejora la viabilidad de las células nucleadas debido a que el tejido adiposo es fragmentado y separado de la porción líquida. ${ }^{18}$ Asimismo, se prefiere el lavado del tejido adiposo antes del procesamiento, ${ }^{19}$ ya que como menciona Keck y colaboradores, ${ }^{20}$ «los anestésicos locales solos o en combinación con la epinefrina reducen la viabilidad celular y la capacidad de diferenciación de la célula madre derivada del tejido adiposo»; por este motivo, el lavado previo al procesamiento con el filtro de acero inoxidable tipo colador resulta un procedimiento relevante en la técnica propuesta. Pawitan realiza una digestión enzimática muy prolongada, lo cual consideramos nocivo para la población celular, es por eso que reducimos el tiempo, pero aumentamos procesos como agitación y temperatura; este paso lo consideramos vital en el resultado.

En segundo lugar, el uso de la temperatura a $40{ }^{\circ} \mathrm{C}$ promueve la homogeneización y digestión del tejido adiposo, realizando así una mejor actividad enzimática en menor tiempo. Esto ya se ha descrito en estudios anteriores, donde se reportó que la variación de 1 o 2 grados en la reacción enzimática conlleva cambios en los resultados de la misma de 10 a $20 \%$, favoreciendo la cinética enzimática, en este caso la colagenasa. ${ }^{21}$ Por último, la agitación constante del tejido adiposo es un paso crucial en la homogeneización de los procesos enzimáticos, provocando que la reacción enzimática se modifique, realizándola en menor tiempo y de manera uniforme. Este último paso también lo utilizaron autores como Yoshimura, Minteer y Almeida, sin embargo, no todos los lo utilizan. ${ }^{13,14,22}$

\section{CONCLUSIÓN}

Concluimos en el presente estudio que la técnica propuesta reduce el tiempo y costo de procesamiento para la obtención de la FVE del tejido adiposo, cuenta con una concentración y viabilidad celular adecuada y es una técnica de corto proceso, económica y accesible, resultando importante su uso en diversas terapias celulares como lipotransferencia celular asistida, cultivos y diferenciación celular.

\section{REFERENCIAS}

1. Argibay P. Medicina regenerativa. Ediciones del Hospital, 2011. pp. 18-19.

2. Magalon G, Daumas A, Sautereau N, Magalon J, Sabatier F, Granel B. Regenerative approach to scleroderma with fat grafting. Clin Plast Surg 2015; 42: 353-364.

3. Rangwala SM, Lazar MA. Transcriptional control of adipogenesis. Ann Rev Nut 2000; 20: 535-559.

4. Deslex S, Negrel R, Vannier C, Etienne J, Ailhaud G. Differentiation of human adipocyte precursors in a chemically defined serum-free medium. Int J Obes 2987; 11 (1): 19-27.

5. Zuk PA, Zhu M, Ashjian P, De Ugarte DA, Huang JI, Mizuno $\mathrm{H}$ et al. Human adipose tissue is a source of 
multipotent stem cells. Mol Biol Cell 2002; 13: 42794295.

6. Rangappa S, Fen C, Lee EH, Bongso A, Sim EK. Transformation of adult mesenchymal stem cells isolated from the fatty tissue into cardiomyocytes. Ann Thorac Surg 2003; 75 (3): 775-779.

7. Ashjian PH, Elbarbary AS, Edmonds B, DeUgarte D, Zhu M, Zuk PA, Lorenz HP, Benhaim P, Hedrick MH. In vitro differentiation of human processed lipoaspirate cells into early neural progenitors. Plast Reconstr Surg 2003; 111: 1922-1931.

8. Safford KM, Hicok KC, Safford SD, Halvorsen YD, Wilkison WO, Gimble JM et al. Neurogenic differentiation of murine and human adipose-derived stromal cells. Biochem Biophys Res Commun 2002; 294 (2): 371-379.

9. Dominici M, Le Blanc K, Mueller I, Slaper-Cortenbach I, Marini F, Krause D et al. Minimal criteria for defining multipotent mesenchymal stromal cells. The International Society for Cellular Therapy Position Statement. Cytotherapy 2006; 8: 315-317.

10. Rodbell M. Metabolism of isolated fat cells. J Biol Chem 1964; 239: 375-380.

11. Sterodimas A, de Faria J, Nicaretta B, Papadopoulos O, Papalambros E, llouz Y-cell-assited lipotransfer. Aesthet Surg J 2010; 30 (1): 78-81.

12. Hamou C, Callaghan MJ, Thangarajah H, Chang E, Chang El, Grogan RH et al. Mesenchymal stem cells can participate in ischemic neovascularization. Plast Reconstr Surg 2009; 123: 45S-55S.

13. Mylotte LA, Duffy AM, Murphy M, O'Brien T, Samali A, Barry $\mathrm{F}$ et al. Metabolic flexibility permits mesenchymal stem cell survival in an ischemic environment. Stem Cells 2008; 26 (5): 1325-1336.

14. Yoshimura K, Sato K, Aoi N, Kurita M, Hirohi T, Harii K. Cell-assisted lipotransfer for cosmetic breast augmentation: supportive use of adipose derived stem/stromal cells. Aesthet Surg J 2008; 32 (1): 48-55. (Discussion 56-57).

15. Sterodimas A, de Faria, J Nicaretta B. Autologous fat transplantation versus adipose derived stem cells enriched lipograft. Aesthet Surg J 2011; 31 (6): 682-689.

16. Yoshimura K, Kuno S. Condensation of tissue and stem cells for fat grafting. Clin Plast Surg 2015; 42: 191-197.

17. Minteer DM, Marra KG, Rubin JP. Adipose stem cells biology, safety, regulation and regenerative potential. Clin Plast Surg 2015; 42: 169-179.

18. Pawitan J, Liem I, Bustami A, Purwoko RY. Simple lipoaspirate washing using a coffee filter. Asian Biomed 2013; 7 (3): 333-338.

19. Gonzales de Buitrago J. Técnicas y métodos de laboratorio clínico. 2 a ed. Barcelona: Masson 2004, pp. 278-279.

20. Keck M, Zeyda M, Gollinger K, Burjak S, Kamolz LP, Frey $M$ et al. Local anesthetics have a major impact on viability of preadipocytes and their differentiation into adipocytes. Plast Reconstr Surg 2010; 126: 1500-1505.

21. Pfeiffer J. Enzymes, the physics and chemistry of life. Ed. New York: Simon and Schuster, 1954, pp. 171-173.

22. Almeida KA, Campa A, Alonso-Vale MIC, Lima FB, Daud ED, Stocchero IN. Fracción vascular estromal de tejido adiposo: cómo obtener células madre y su rendimiento de acuerdo a la topografía de las áreas donantes: estudio preliminar. Cir Plast Iberolatinoam 2008; 34: 71-79.

Correspondencia:

Dr. Wilder Antonio Pérez Willis

Clínica Continental

Avenida San Borja Sur Núm. 526,

San Borja, Lima, Perú.

E-mail:wperezwillis@gmail.com 